\title{
En mann i 60-årene med alvorlig respirasjonssvikt
}

\author{
En mann i begynnelsen av 60-årene med kjent lungesarkoidose ble \\ henvist for utredning med henblikk på lungetransplantasjon på grunn av \\ alvorlig respirasjonssvikt. Anamnestiske opplysninger gjorde at det ble \\ påvist en tilstand som krevde en helt annen behandling enn først antatt.
}

Se kommentar side 1657

\author{
Anne Naalsund \\ anne.naalsund@oslo-universitetssykehus.no \\ May-Brit Lund \\ Lungeavdelingen \\ Georg Mynarek \\ Avdeling for radiologi og nukleærmedisin \\ Svend Aakhus \\ Kardiologisk avdeling \\ Kirsten Muri Boberg \\ Avdeling for organtransplantasjon, \\ fordøyelses- og nyresykdommer

\section{Ingvild Nordøy} \\ Seksjon for klinisk immunologi \\ og infeksjonssykdommer
}

Oslo universitetssykehus, Rikshospitalet

Pasienten hadde vel 20 år tidligere fått diagnosen sarkoidose basert på transbronkiale biopsier som viste granulomatøs betennelse. Ti år senere fikk han påvist immunsvikt av type vanlig variabel immunsvikt (common variable immune deficiency, CVID) og startet substitusjonsbehandling med immunglobulin. Utfall i biokjemiske leverprøver to år senere førte til leverbiopsi som viste granulomer forenlig med sarkoidose. De siste to år hadde pasienten tiltakende dyspné og respirasjonssvikt, og hadde startet med langtidsbehandling med oksygen. På henvisningstidspunktet viste arteriell blodgassanalyse $\left(\mathrm{pO}_{2}\right.$ (a)) 7,1 $\mathrm{kPa}(10,0-14,0 \mathrm{kPa})$ med oksygen $3 \mathrm{l} / \mathrm{min}$ på nesekateter. Han trengte oksygen $8 \mathrm{l} / \mathrm{min}$ for å komme opp i $\mathrm{pO}_{2} 8,0 \mathrm{kPa}$. Røntgen thorax var uendret over flere år og viste sparsomme fibrøse drag (fig 1). Spirometri var også uendret, med verdier midt i det forventede området. Gassdiffusjonskapasitet var imidlertid redusert til $48 \%$ av forventet. Tre ukers behandling med prednisolon $20 \mathrm{mg}$ daglig var forsøkt uten effekt på symptomer, lungefunksjon eller blodgasser. Han ble derfor henvist for vurdering av lungetransplantasjon, eventuelt optimalisering av behandling for sarkoidose.
Pasienten hadde i løpet av en toårsperiode utviklet respirasjonssvikt med stort oksygenbehov uten at det radiologisk eller spirometrisk var tilkommet forandringer som forklarte utviklingen. Hvis sarkoidose var årsaken, måtte forklaringen være sarkoidoseassosiert pulmonal hypertensjon. Dette kunne passe med redusert gassdiffusjonskapasitet. I henvisningen var det imidlertid anført at det var normale funn ved ekkokardiografi og at det ikke var funnet tegn til forhøyet trykk i det lille kretsløp. Det var lite sannsynlig at fibrose kunne forklare respirasjonssvikten, ettersom de radiologiske forandringene var beskjedne og han hadde normale spirometriverdier. Lungetransplantasjon er et behandlingstilbud for selekterte pasienter med kronisk respirasjonssvikt som følge av lungesykdom i sluttstadiet. Det eksisterer nasjonale og internasjonale retningslinjer for seleksjon av pasienter som kan tilbys slik behandling (1). Sarkoidose med respirasjonssvikt og eventuelt pulmonal hypertensjon er en tilstand der lungetransplantasjon kan være aktuelt. Immunsvikt er en relativ kontraindikasjon mot lungetransplantasjon. Pasienter med vanlig variabel immunsvikt som får adekvat substitusjonsbehandling og ikke har alvorlige infeksjonsproblemer, kan imidlertid aksepteres hvis de ellers fyller kriteriene og ikke har andre kontraindikasjoner.

Da pasienten ble innlagt på Rikshospitalet, hadde han leppe- og neglesengcyanose til tross for oksygen $8 \mathrm{l} / \mathrm{min}$ på nesekateter. Ved klinisk undersøkelse var det normal respirasjonslyd og ingen fremmedlyder over lungene. Han hadde ingen spidernævi. Blodprøver viste SR 1 og Hb 17,7 g/100 ml (12-15). Han hadde forhøyet laktatdehydrogenase 302 U/l (105-205), alkalisk fosfatase 144 U/L (35- 105) og bilirubin $64 \mathrm{\mu mol} / \mathrm{l}(5-25)$ og lav $\lg$ 3,2 g/l $(6,1-14,9)$. ASAT, ALAT, totalprotein og albumin var innen normalområdet. Lungefunksjonsunders $ø$ kelser viste forsert vitalkapasitet 4,0 ( (102\% av forventet,) forsert ekspiratorisk volum $i$ ett sekund 3,2 l
1104\% av forventet) og gassdiffusjonskapasitet 3,7SI-enheter (42\% av forventet). Høyresidig hjertekateterisering viste normalt trykk i det lille kretsløp og normal lungekarmotstand.

Blodprøvene var til liten hjelp for videre utredning utover å verifisere vanlig variabel immunsvikt som var inadekvat behandlet. Utfallene i leverprøver var marginale, bortsett fra at bilirubinverdiene var forhøyet. Lungefunksjonsmålingene bekreftet at pasienten hadde normal belgfunksjon, men redusert gassdiffusjonskapasitet. Ekkokardiografi hadde ikke gitt holdepunkter for pulmonal hypertensjon. Dette ble bekreftet ved høyresidig hjertekateterisering. Hvorfor hadde pasienten alvorlig respirasjonssvikt? Med normal belgfunksjon, radiologisk beskjedne fibroseforandringer og normalt trykk $\mathrm{i}$ det lille kretsløp kunne ikke lungesarkoidose være årsaken. I så fall ville vi forventet betydelig redusert lungefunksjon ved spirometri, eller ved isolert nedsatt gassdiffusjon en alvorlig grad av pulmonal hypertensjon.

Pasienten fortalte at han bare brukte oksygentilførsel på dagtid. Om natten sov han godt uten oksygentilførsel og våknet uthvilt om morgenen. På grunn av disse opplysningene ble blodgasser målt $i$ liggende og sittende stilling uten oksygentilførsel. Målt $i$ sittende stilling ble det funnet $\mathrm{pO}_{2}$ (a) 6,4 $\mathrm{kPa}(10-14)$, $\mathrm{O}_{2}$-metning $84 \%, \mathrm{pCO}_{2}(\mathrm{a}) 3,0 \mathrm{kPa}$. Liggende flatt $i$ seng var tilsvarende verdier $\mathrm{pO}_{2}$ (a) $8,4 \mathrm{kPa}, \mathrm{O}_{2}$ metning $93 \%, \mathrm{pCO}_{2}(\mathrm{a}) 3,2 \mathrm{kPa}$.

Blodgassundersøkelsene avdekket betydelig respirasjonssvikt i sittende stilling som bedret seg når pasienten la seg ned. Dyspné $\mathrm{i}$ sittende og stående stilling som bedres eller oppheves i horisontalt leie, kalles platypné. Redusert oksygenmetning i stående stilling som bedres i horisontalt leie, kalles ortodeoksi. Platypné og ortodeoksi er sjeldne fenomener, oftest assosiert med intrakardial shunting som ved åpentstående foramen ovale eller interatriale defekter. Ved ekkokardiografi så man imidlertid ikke tegn til hjertesykdom. En annen årsak til platypné er intrapulmonal shunting. Pulmonalkretsløpet er et lavtrykksystem, og både perfusjon og ventilasjon foregår mest $i$ basale lungeavsnitt. Ved shunting intrapulmonalt vil ventilasjon-perfusjons-forholdene bedres når pasienten legger seg ned, mens mer blod passerer via shunter i oppreist stilling. Intrapulmonal shunting ses særlig ved kroniske 
leversykdommer, og konstellasjonen leversykdom og shunting kalles hepatopulmonalt syndrom. Slik shunting opptrer også ved avgrensede solitære eller multiple anatomiske atrioventrikulære malformasjoner, ofte assosiert med Oslers sykdom. Den videre utredningen tok derfor sikte på å kartlegge om det forelå intrapulmonal shunting, eventuelt finne årsaken til denne, og beregne shuntfraksjonen.

Tilsendte røntgenundersøkelser fra henvisende sykehus ble revurdert. Som bifunn på CT av thorax/ øvre abdomen tatt ti måneder før innleggelse på Rikshospitalet ble det bemerket at det forelå åpentstående umbilikalvene samt slyngede vener $i$ øvre abdomen som ga mistanke om portal hypertensjon (fig 2).

Påvisning av åpentstående eller rekanalisert umbilikalvene på CT kan være et uspesifikt funn, men skyldes ofte portal hypertensjon med utvikling av kollateralt kretsløp. Portal hypertensjon kan være assosiert med hypoksemi via flere mekanismer: portopulmonal hypertensjon, hypoksemi sekundært til hydrothorax/ascites ved leversvikt eller hepatopulmonalt syndrom.

Det ble gjort CT av lever/øvre abdomen med intravenøs kontrast som viste at leveren var liten med grovbuklet overflate som ved cirrhose og at det forelå massivt utviklet kollateralkretsløp i form av rekanalisert vena umbilicalis samt kollateraler i milthilus og langs ventrikkelens minorside til distale oesophagus som tegn på portal hypertensjon. Det var ingen fokale lesjoner.

Pasienten hadde avansert leversykdom med portal hypertensjon, til tross for beskjedne utfall i biokjemiske leverprøver. Bortsett fra at det $\mathrm{i}$ en leverbiopsi mange år tidligere var påvist granulomer, hadde han ingen kjent leversykdom. Riktignok er lever nesten alltid affisert ved sarkoidose i gastrointestinalkanalen, men alvorlig leversykdom med portal hypertensjon utvikles sjelden (2). Vår pasient hadde imidlertid også vanlig variabel immunsvikt, som er assosiert både med autoimmune manifestasjoner og med granulomatøs inflammasjon i ulike organer, inklusive lever (3). Patologisk kan tilstanden imitere sarkoidose $(4,5)$. Leveraffeksjon ved vanlig variabel immunsvikt har oftest et mildt forløp, men kolestase og utvikling av portal hypertensjon forekommer $(6,7)$.

For å verifisere diagnosen hepatopulmonalt syndrom, måtte en eventuell shunting fremstilles visuelt og shuntstørrelse beregnes. Ekkokardiografi med saltvannskontrast kan benyttes for å påvise intrapulmonal eller intrakardial shunting (8). Kontrasten lages ved å løse $0,5 \mathrm{ml}$ romluft fysikalsk i $9,5 \mathrm{ml}$ fysiologisk saltvann, som så infunderes som bolus $i$ en kubitalvene. Gassboblene i saltvannet vil normalt kun gjenfinnes $i$ høyre hjertehalvdel, fordi de filtreres bort i lungekarsengen. Hvis det foreligger en høyrevenstre-shunt, vil gassbobler også gjenfinnes i venstre hjertehalvdel. For å skille intrakardiale og intrapulmonale shunter måles tiden det tar før gassboblene gjenfinnes i venstre hjertehalvdel. Ved en intrakardial høyre-venstre-shunt kan gassboblene ses i venstre hjertehalvdel innen tre hjerteslag etter at kontrasten har nådd høyre atrium. Hvis det foreligger en intrapulmonal shunt, vil det ta mer enn tre hjerteslag før gassboblene gjenfinnes i venstre hjertehalvdel.

Det ble utført ekkokardiografi med intravenøs saltvannskontrast (fig 3). Hos vår pasient ble det observert overgang av gassbobler fra høyre til venstre hjertehalvdel 4-5 hjerteslag etter injeksjon. Dette indikerte at det forelå en høyre til venstre intrapulmonal shunt. For å beregne shuntfraksjonen ble det utført nukleærmedisinsk scintigrafi med intravenøs injeksjon av $99 m$ Tc-MAA, og deretter registrering av helkroppsscintigrammer fra ventral- og dorsalsiden. Gjennomsnittsverdi forfra og bakfra ble beregnet til $25 \%$, altså en signifikant shunting og i overensstemmelse med visuell bedømmelse av scintigrammene.

Beregning av shunten baseres på lekkasje av isotopen forbi lunger til det systemiske kretsløpet. Ved technetiumscintigrafi benyttes makroaggregert albumin $>20 \mu \mathrm{m}$ i diameter, som normalt fanges opp i mikrokapillærene i lungekarsengene, som har en diameter på $8-15 \mu \mathrm{m}$. Grad av isotopopptak i andre organer (hjerne, nyrer) reflekterer mengden kontrast som har omgått lungekapillærsengen via intrapulmonal eller intrakardial shunting. Hos vår pasient var intrakardial shunting ekskludert ved ekkokardiografi med saltvannskontrast. Verken ekkokardiografi eller nukleærmedisinsk shuntkvantitering kan skille lokaliserte $\mathrm{AV}$-malformasjoner fra diffuse dilatasjoner i lungekarsengen. Hepatopulmonalt syndrom er primært assosiert med diffuse dilatasjoner, men avgrensede shunter tilgjengelig for embolisering er beskrevet (9).

Pasienten ble utskrevet med en annen diagnose enn den han kom inn med. Lungetransplantasjon - som han var henvist for - var ikke aktuelt fordi hans granulomatøse lungesykdom ikke var årsak til respirasjonssvikten. Han ble i stedet utredet for levertransplantasjon, som er den eneste behandlingsformen med kurativt siktemål ved hepatopulmonalt syndrom. Som ledd i utredningen ble det tatt ny leverbiopsi som viste nodulær regenerativ hyperplasi og portal betennelse. Et slikt funn forekommer hyppig ved leverpatologi assosiert med vanlig variabel immunsvikt (6). Portal hypertensjon ble bekreftet ved venografi med wedge-trykkmåling av portvenetrykket via en levervene $115-17 \mathrm{~mm} \mathrm{Hg}$ mot normalt ca. $7 \mathrm{~mm} \mathrm{Hg}$ ). Pasienten er senere blitt levertransplantert.
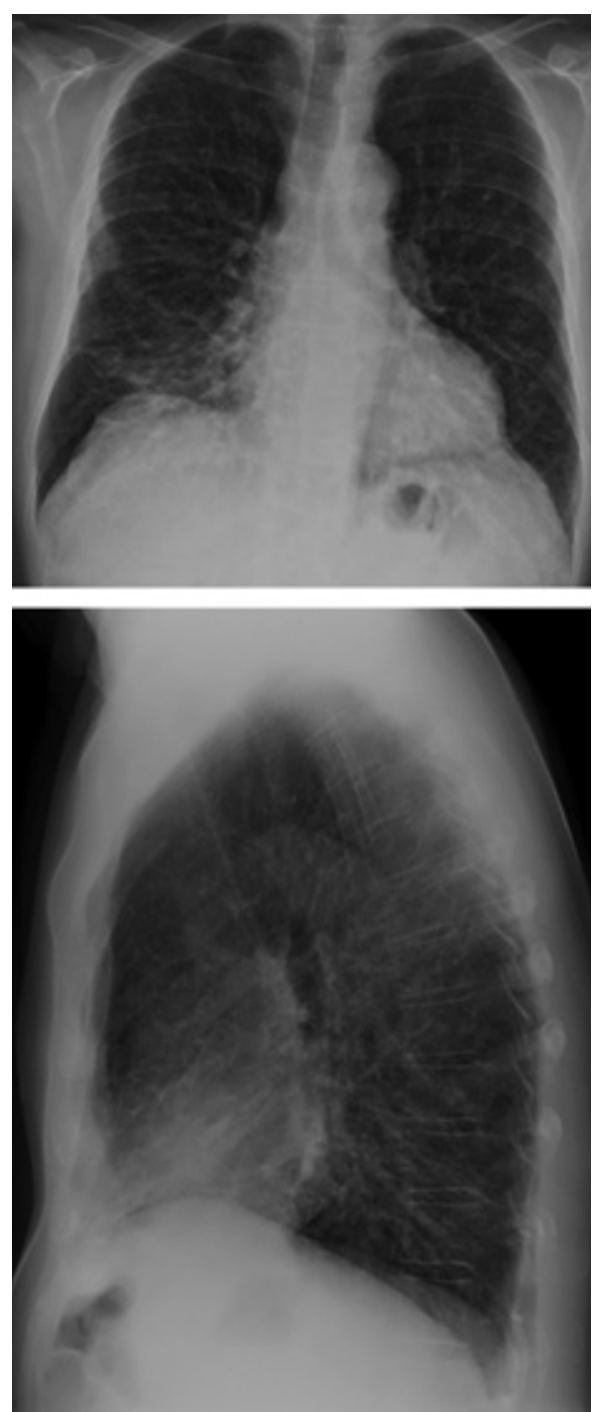

Figur 1 Røntgen thorax viser interstitielle fibrøst pregede fortetninger spredt i begge lunger, hovedsakelig perihilært i basale avsnitt

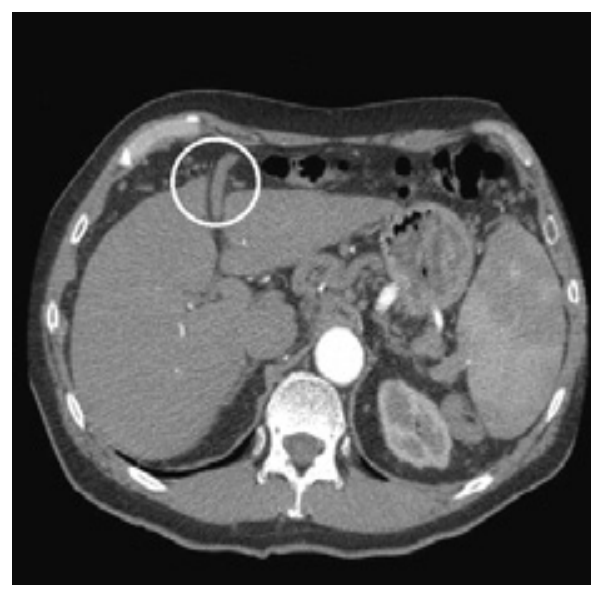

Figur 2 CT-abdomen i tidlig arteriell fase viser åpentstående umbilikalvene som ga mistanke om portal hypertensjon

\section{Diskusjon}

Hepatopulmonalt syndrom er karakterisert ved hypoksemi forårsaket av utvidelse av pulmonalkarsengen hos pasienter med leversykdom (10). Avhengig av diagnos- 


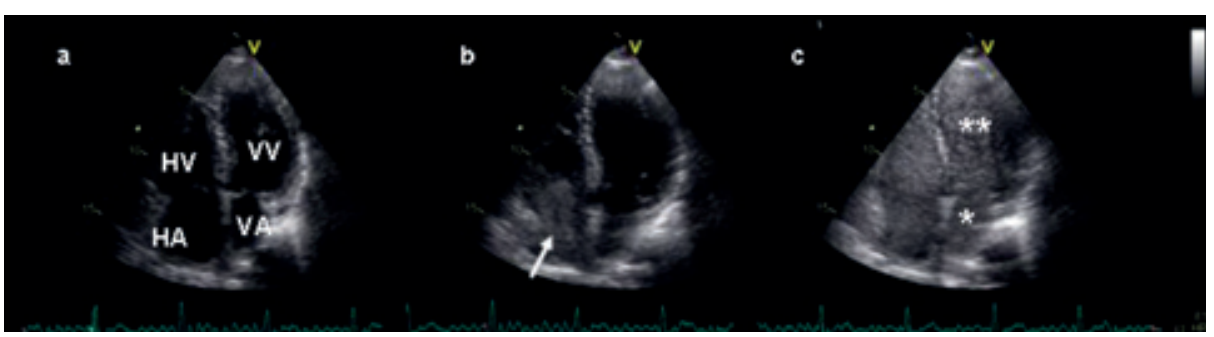

Figur 3 Transtorakal ekkokardiografi. Apikal firekammer registrering. a) Før infusjon av saltvannskontrast. $H A=$ høyre atrium, $H V=$ høyre ventrikkel, $V A=$ venstre atrium, $V V=$ venstre ventrikkel. b) saltvannskontrast fyller HA (pil), c) seks hjertesykluser etter fylt saltvannskontrast i VA (*) og WV (**) som tegn på transpulmonal shunting

tiske kriterier ses tilstanden hos $4-47 \%$ av pasienter med kronisk leversykdom $(10,10-$ 15). Debutsymptomet er oftest dyspné hos pasienter med mangeårig leversykdom. Hos vår pasient ble utredningen forsinket fordi man ikke hadde erkjent at pasienten hadde en leversykdom da han utviklet respirasjonssvikt. Pasientens opplysninger om bedring av dyspné i liggende stilling (platypné) og påvisning av økende hypoksemi stående (ortodeoksi) illustrerer verdien av en god sykehistorie. Informasjonen bidro til at det ble utført undersøkelser som påviste intrapulmonal shunting.

Hypoksemi ved hepatopulmonalt syndrom omfatter ventilasjon-perfusjon-uforlikelighet, intrapulmonal shunting og redusert oksygendiffusjon (fig 4). Hovedårsaken er shunting. Mekanismen er utvikling av intrapulmonal vaskulær dilatasjon på kapillærnivå. Diffus dilatasjon av den pulmonale sirkulasjon fører til høyre-venstre-shunt, passasje av ikke-oksygenert blod til venstre

hjertehalvdel og dermed hypoksemi. Patofysiologisk fungerer riktignok ikke intrapulmonal vaskulær dilatasjon som sanne anatomiske shunter, fordi oksygeneringen bedres noe ved innånding av $100 \%$ oksygen. Den antatte mekanismen ved intrapulmonal vaskulær dilatasjon er at oksygenmolekyler ikke når å diffundere fra alveol til sentrum av det korresponderende dilaterte karet for å oksygenere hemoglobinet i røde blodlegemer. Tilførsel av oksygen øker strømmen av oksygenmolekyler, slik at perfusjonsdefekten reduseres. Dette forklarer hvorfor vår pasient til en viss, men beskjeden grad, responderte på oksygentilførsel.

Årsaken til intrapulmonal vaskulær dilatasjon er ikke klarlagt. Nedsatt evne til eliminasjon av sirkulerende pulmonale vasodilatatorer på grunn av sviktende leverfunksjon er foreslått - likeledes at en skadet lever danner stoffer med vasodilaterende egenskaper. Klinisk ser det ut til at forekomst av spidernævi er positivt korrelert til grad av

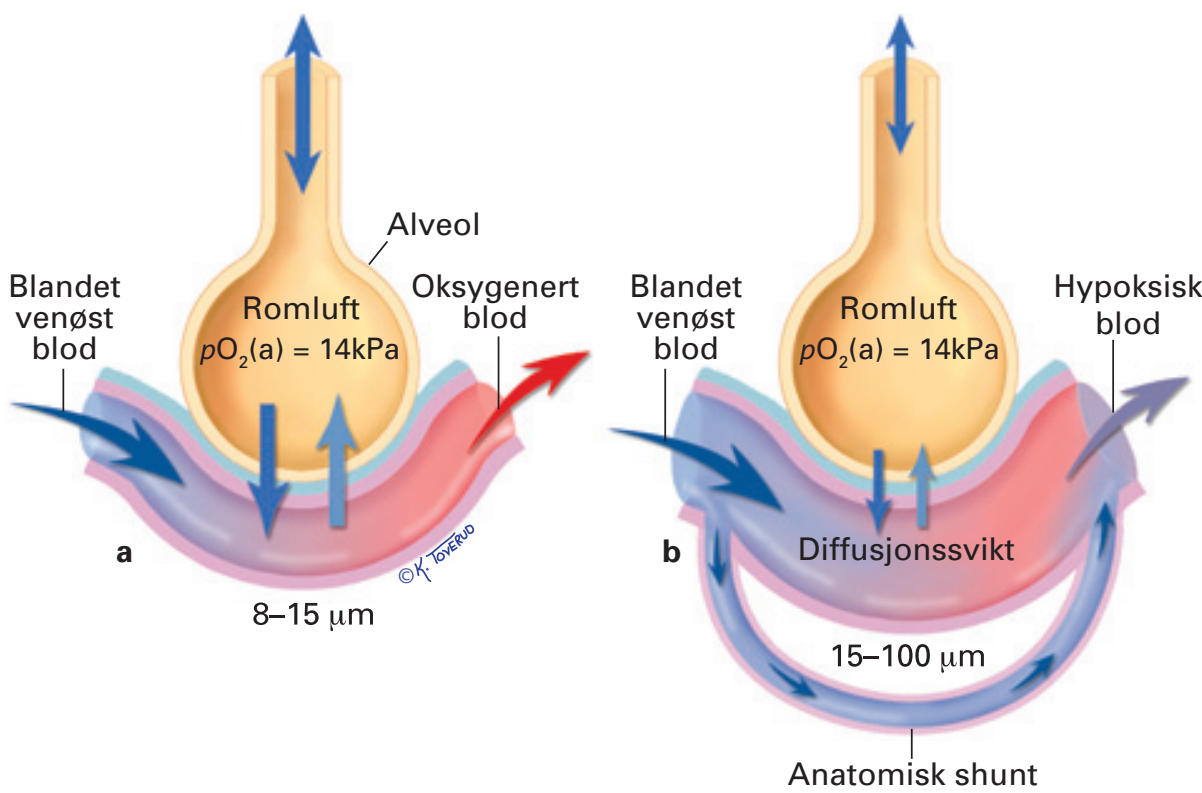

Figur 4 Mekanismer ved utvikling av hypoksemi hos pasient med hepatopulmonalt syndrom. Hos en frisk person (a) som har jevn alveolær ventilasjon og normale dimensjoner på pulmonalkarene, har kapillærene en diameter på 8-15 $\mu \mathrm{m}$. Oksygen diffunderer inn i karet, og forholdet mellom ventilasjon og perfusjon er normalt. Hos en pasient med hepatopulmonalt syndrom er mange kapillærer utvidet og blodgjennomstrømningen dermed ujevn. Derfor forrykkes forholdet mellom ventilasjon og perfusjon, og sammen med nedsatt oksygendiffusjon til sentrum av utvidede kapillærer, ofte også med anatomisk shunting, fører disse forholdene til varierende grad av hypoksemi. Ved $\mathrm{O}_{2}$-tilførsel øker partialtrykket av oksygen i alveolene. Dermed øker gradienten for diffusjon av $\mathrm{O}_{2}$, og oksygeneringen bedres. Dette i motsetning til ved en ren anatomisk shunt der oksygeneringen ikke bedres, selv ved $100 \% \mathrm{O}_{2}$-tilførsel pulmonal vasodilatasjon og til forstyrrelser i gassutvekslingen (16). Nitrogenoksid (NO) har en rolle ved hepatopulmonalt syndrom $(17,18)$. Dette er grunnlaget for bruk av vasokonstriktive preparater - som NOhemmere - som korttidsbehandling for hypoksemi ved hepatopulmonalt syndrom for og etter levertransplantasjon.

Hvilken tilstand lå til grunn for leversykdom hos vår pasient? Var det sarkoidose med vanlig variabel immunsvikt? Eller var granulomene i lunge- og leverbiopsiene en vevsrespons ved vanlig variabel immunsvikt? Pasienter med denne sykdommen kan ha autoimmune manifestasjoner i flere organer, og disse kan debutere før hypogammaglobulinemi påvises. Vår pasient kan primært ha hatt vanlig variabel immunsvikt, selv om lungeforandringene kom tidlig og leverforandringene senere. Portal hypertensjon og kolestase er de hyppigste manifestasjonene på leversykdom ved denne lidelsen, men ses sjelden ved sarkoidose (6). Påvisning av nodulær regenerativ hyperplasi i den siste leverbiopsien passer med histologiske forandringer i lever hos pasienter med vanlig variabel immunsvikt og tilskrives autoimmune mekanismer (6). Disse pasientene kan utvikle et sarkoidoseliknende sykdombilde med granulomer i lunger og lever (5). Patogenesen er ukjent, men forhøyet nivå av tumornekrosefaktor (TNF) på bakgrunn av TNF-polymorfisme er foreslått (19).

Hvordan behandles hepatopulmonalt syndrom? Ulike tilnærminger for å bedre oksygeneringen har vært forsøkt: embolisering av intrapulmonale AV-malformasjoner, medikamenter med vasokonstriktive egenskaper og optimalisert behandling av leversykdommen. Ingen har hatt særlig effekt på graden av shunting $(10,12,17,20,21)$. Den mest lovende behandlingen er levertransplantasjon. Internasjonale transplantasjonssentre har rapportert betydelig bedring av hypoksemi og reduksjon av intrapulmonal shunting, men dette kan ta uker til måneder. Mortaliteten etter levertransplantasjon er imidlertid høyere hos pasienter med hepatopulmonalt syndrom enn hos pasienter uten. Transplantasjonsvurdering anbefales $\mathrm{i}$ The American Association for the Study of Liver Diseases Practice Guidelines (22-27).

Pasienten har gitt samtykke til at artikkelen blir publisert.

\section{Anne Naalsund (f. 1945)}

er spesialist i indremedisin og i lungesykdommer. Hun er overlege ved Lungeavdelingen, Oslo universitetssykehus, Rikshospitalet. Ingen oppgitte interessekonflikter.

\section{May-Brit Lund (f. 1949)}

er dr.med. og spesialist i indremedisin og i lungesykdommer. Hun er overlege ved Lungeavdelingen, Oslo universitetssykehus, Rikshospitalet.

Ingen oppgitte interessekonflikter. 


\section{Georg Mynarek (f. 1961)}

er spesialist i indremedisin og i radiologi. Han er overlege ved Avdeling for radiologi og nukleærmedisin, Oslo universitetssykehus, Rikshospitalet, har de siste årene jobbet med CT og lungeproblemstillinger og har ansvar for CT-intervensjon.

Ingen oppgitte interessekonflikter.

\section{Svend Aakhus (f. 1958)}

er dr.med. og spesialist i indremedisin og hjertesykdommer. Han overlege og seksjonsleder for Seksjon for hjerteultralyd, kardiologisk avdeling, Oslo universitetssykehus, Rikshospitalet og professor II ved Norges teknisknaturvitenskapelige universitet.

Ingen oppgitte interessekonflikter.

\section{Kirsten Muri Boberg (f. 1953)}

er dr.med. og spesialist i anestesiologi og $\mathrm{i}$ indremedisin og ford øyelsessykdommer. Hun er overlege ved Avdeling for organtransplantasjon, fordøyelses- og nyresykdommer. Oslo universitetssykehus, Rikshospitalet. Ingen oppgitte interessekonflikter.

\section{Ingvild Nordøy (f. 1960)}

er dr.med. og spesialist i indremedisin og infeksjonssykdommer og i medisinsk mikrobiologi. Hun er overlege ved Seksjon for klinisk immunologi og infeksjonssykdommer, Oslo universitetssykehus, Rikshospitalet. Oppgitte interessekonflikter: Har fått foredragshonorar fra GlaxoSmithKline og dekning av kostnader til konferanse fra MSD og Gilead.
Litteratur

1. Bjørtuft O, Geiran O. Lungetransplantasjon - etab lert behandling, udekket behov. Tidsskr Nor Lægeforen 2003; 123: 3206-9.

2. Ebert EC, Kierson M, Hagspiel KD. Gastrointestinal and hepatic manifestations of sarcoidosis. Am J Gastroenterol 2008; 103: 3184-92, quiz 3193.

3. Agarwal S, Cunningham-Rundles $C$. Autoimmunity in common variable immunodeficiency. Curr Allergy Asthma Rep 2009: 9: 347-52.

4. Wang J, Cunningham-Rundles C. Treatment and outcome of autoimmune hematologic disease in common variable immunodeficiency (CVID). J Autoimmun 2005; 25: 57-62

5. Fasano MB, Sullivan KE, Sarpong SB et al. Sarcoidosis and common variable immunodeficiency. Report of 8 cases and review of the literature. Medicine (Baltimore) 1996: 75: 251-61.

6. Malamut G, Ziol M, Suarez F et al. Nodular regenerative hyperplasia: the main liver disease in patients with primary hypogammaglobulinemia and hepatic abnormalities. J Hepatol 2008; 48: 74-82.

7. Biøro K, Haaland T, Skaug K et al. The spectrum of hepatobiliary disease in primary hypogammaglobulinaemia. J Intern Med 1999; 245: 517-24.

8. Nanthakumar K, Graham AT, Robinson TI et al. Contrast echocardiography for detection of pulmonary arteriovenous malformations. Am Heart J 2001: 141: 243-6.

9. Poterucha JJ, Krowka MJ, Dickson ER et al. Failure of hepatopulmonary syndrome to resolve after liver transplantation and successful treatment with embolotherapy. Hepatology 1995: 21: 96-100.

10. Rodríguez-Roisin R, Krowka MJ, Hervé $P$ et al. Pulmonary-Hepatic vascular Disorders (PHD) Eur Respir J 2004; 24: 861-80.

11. Krowka MJ, Cortese DA. Hepatopulmonary syndrome. Current concepts in diagnostic and therapeutic considerations. Chest 1994; 105: 1528-37.

12. Schenk P, Schöniger-Hekele M, Fuhrmann V et al. Prognostic significance of the hepatopulmonary syndrome in patients with cirrhosis. Gastroenterology 2003; 125: 1042-52

13. Krowka MJ, Tajik AJ, Dickson ER et al. Intrapulmonary vascular dilatations (IPVD) in liver transplant candidates. Screening by two-dimensional contrast-enhanced echocardiography. Chest 1990 97: $1165-70$.

14. Hopkins WE, Waggoner AD, Barzilai B. Frequency and significance of intrapulmonary right-to-left shunting in end-stage hepatic disease. Am J Cardiol 1992: 70: 516-9.
15. Arguedas MR, Singh H, Faulk DK et al. Utility of pulse oximetry screening for hepatopulmonary syndrome. Clin Gastroenterol Hepatol 2007; 5: 749-54.

16. Rodriguez-Roisin R, Roca J, Agusti AG et al. Gas exchange and pulmonary vascular reactivity in patients with liver cirrhosis. Am Rev Respir Dis 1987; 135: 1085-92

17. Fallon MB, Abrams GA. Hepatopulmonary syndrome. Curr Gastroenterol Rep 2000; 2: 40-5.

18. Zhang HY, Han DW. Zhao ZF et al. Multiple pathogenic factor-induced complications of cirrhosis in rats: a new model of hepatopulmonary syndrome with intestinal endotoxemia. World J Gastroentero 2007; 13: $3500-7$.

19. Mullighan CG, Fanning GC, Chapel HM et al. TNF and lymphotoxin-alpha polymorphisms associated with common variable immunodeficiency: role in the pathogenesis of granulomatous disease. J Immunol 1997: 159. 6236-41.

20. Schenk P, Madl C, Rezaie-Majd S et al. Methylene blue improves the hepatopulmonary syndrome. Ann Intern Med 2000; 133: 701-6.

21. Castro M, Krowka MJ. Hepatopulmonary syndrome. A pulmonary vascular complication of liver disease. Clin Chest Med 1996; 17: 35-48

22. Swanson KL, Wiesner RH, Krowka MJ. Natural history of hepatopulmonary syndrome: Impact of liver transplantation. Hepatology 2005: 41: 1122-9.

23. Collisson EA, Nourmand $\mathrm{H}$, Fraiman $\mathrm{MH}$ et at. Retrospective analysis of the results of liver trans plantation for adults with severe hepatopulmonary syndrome. Liver Transpl 2002; 8: 925-31.

24. Taillé C. Cadranel J, Bellocq A et al. Liver transplantation for hepatopulmonary syndrome: a tenyear experience in Paris, France. Transplantation 2003; 75: 1482-9, discussion 1446-7.

25. Deberaldini M, Arcanjo AB, Melo E et al. Hepatopulmonary syndrome: morbidity and survival after liver transplantation. Transplant Proc 2008; 40: 3512-6.

26. Gupta S, Castel H, Rao RV et al. Improved survival after liver transplantation in patients with hepatopulmonary syndrome. Am J Transplant 2010; 10: 354-63.

27. Swanson KL. Should we screen for hepatopulmo nary syndrome in liver transplant candidates? Liver Transpl 2007; 13: 183-4.

Mottatt 21.1. 2011, første revisjon innsendt 31.3. 2011, godkjent 14.4. 2011. Medisinsk redaktør Lars Frich.

\section{Levertransplantasjon i stedet for lungetransplantasjon}

Denne kasuistikken omhandler en 60 år gammel mann der man ser en 20 år gammel sarkoidosediagnose mot en mer sannsynlig diagnose, nemlig immunglobulinmangel (vanlig variabel immunsvikt; common variable immune deficiency, CVID). Og i kasuistikken konkluderer man med indikasjon for levertransplantasjon der henvisningsdiagnosen var «indikasjon for lungetransplantasjon?». Vi snakker om en relativt sjelden fugl, hepatopulmonalt syndrom. Til tross for avansert leversykdom med portal hypertensjon, finnes det $\mathrm{i}$ de aktuelle tilfellene beskjedne utfall i biokjemiske leverprøver, med normal albumin og INR og kun lett forhøyet ALP, LD og bilirubin. Kasuistikken er meget illustrativ og godt diskutert og til glede for klinikere med sans for patofysiologiske mekanismer.
Kasuistikken er også et eksempel på hva en årvåken kliniker kanskje kunne erkjent tidligere hvis anamnesen og observasjonen hadde vært mer inngående. Her kommer det frem opplysninger om både platypné (dyspné i sittende/stående som forsvinner i horisontalt leie) og ortodeoksi (redusert oksygenmetning i stående som bedres i horisontalt leie), eller som denne pasienten forklarer det: «Jeg bruker langtidsbehandling med oksygen bare på dagtid». Så kunne kanskje også en årvåken radiolog oppdaget en åpentstående umbilikalvene på en tidligere CTundersøkelse.

Vanlig variabel immunsvikt kan manifestere seg på svært forskjellige måter, som antydet ved ordet «variabel». De fleste har hatt symptomer i mange år før diagnosen stilles. Typisk er en person i alderen 20-40 år. Til- standen har høy prevalens i Nord-Europa (1). Det vanligste er:

- tilbakevendende infeksjoner (særlig øvre og nedre luftveier, med økt risiko for utvikling av bronkiektasier (hos opptil 50\%))

- autoimmune tilstander (hos nærmere $25 \%$, særlig hemolytisk anemi og trombocytopeni, revmatoid artritt og pernisiøs anemi)

- gastrointestinale tilstander (vanligste symptom er diaré, som oftest inflammatorisk tarmsykdom og leveraffeksjon)

- økt risiko for malignitet (oftest lymfom)

Det er rapportert funn av ikke-nekrotiserende granulomater hos opptil $20 \%$ av personer med immunglobulinmangel (2). Avgrensningen til sarkoidose kan dermed være utfordrende. I en undersøkelse har man funnet immunglobulinmangel hos hele $10 \%$ av personer med dia- 